ARTICLE

\title{
ENPP1-Fc prevents mortality and vascular calcifications in rodent model of generalized arterial calcification of infancy
}

Ronald A. Albright ${ }^{1, \star}$, Paul Stabach ${ }^{1, \star}$, Wenxiang Cao ${ }^{2}$, Dillon Kavanagh${ }^{1}$, Isabelle Mullen${ }^{1}$, Alexander A. Braddock', Mariel S. Covo', Martin Tehan', Guangxiao Yang1', Zhiliang Cheng ${ }^{3}$, Keith Bouchard 3 , Zhao-Xue $\mathrm{Yu}^{3}$, Stephanie Thorn ${ }^{4}$, Xiangning Wang ${ }^{4}$, Ewa J. Folta-Stogniew ${ }^{5}$, Alejandro Negrete ${ }^{6}$, Albert J. Sinusas ${ }^{4}$, Joseph Shiloach ${ }^{6}$, George Zubal', Joseph A. Madri', Enrique M. De La Cruz ${ }^{2}$ $\&$ Demetrios T. Braddock ${ }^{1}$

Diseases of ectopic calcification of the vascular wall range from lethal orphan diseases such as generalized arterial calcification of infancy (GACI), to common diseases such as hardening of the arteries associated with aging and calciphylaxis of chronic kidney disease (CKD). GACl is a lethal orphan disease in which infants calcify the internal elastic lamina of their medium and large arteries and expire of cardiac failure as neonates, while calciphylaxis of CKD is a ubiquitous vascular calcification in patients with renal failure. Both disorders are characterized by vascular Mönckeburg's sclerosis accompanied by decreased concentrations of plasma inorganic pyrophosphate $\left(\mathrm{PP}_{\mathrm{i}}\right)$. Here we demonstrate that subcutaneous administration of an ENPP1-Fc fusion protein prevents the mortality, vascular calcifications and sequela of disease in animal models of $\mathrm{GACl}$, and is accompanied by a complete clinical and biomarker response. Our findings have implications for the treatment of rare and common diseases of ectopic vascular calcification.

\footnotetext{
${ }^{1}$ Department of Pathology, Yale University School of Medicine, New Haven, Connecticut 06510, USA. ${ }^{2}$ Department of Molecular Biophysics and Biochemistry, Yale University, New Haven, Connecticut 06520, USA. ${ }^{3}$ Alexion, Cheshire, Connecticut 06410, USA. ${ }^{4}$ Department of Medicine and Diagnostic Radiology, Yale University School of Medicine, New Haven, Connecticut 06510, USA. ${ }^{5}$ WM Keck Biotechnology Research Laboratory, Yale University School of Medicine, New Haven, Connecticut 06511, USA. ${ }^{6}$ Biotechnology Core Laboratory, National Institute of Diabetes and Digestive Kidney Diseases, National Institutes of Health, Rockville, Maryland 20852, USA. ${ }^{7}$ Z-Concepts LLC, East Haven, Connecticut 06512, USA. ${ }^{*}$ These authors contributed equally to the work. Correspondence and requests for materials should be addressed to D.T.B. (email: demetrios.braddock@yale.edu).
} 
G eneralized arterial calcification of infancy (GACI) is an ultra-rare neonatal disease characterized by infantile onset of widespread arterial calcifications in large and mediumsized vessels resulting in cardiovascular collapse and death in the neonatal period. The disease presents clinically with heart failure, respiratory distress, hypertension, cyanosis and cardiomegaly. The prognosis is grave, with older reports of an $85 \%$ mortality rate at 6 months $^{1}$, while recently intensive treatment with bisphosphonates has lowered mortality to $55 \%$ at 6 months $^{2}$. Tempering this apparent progress is the severe skeletal toxicity associated with prolonged use of etridonate in patients with GACI (ref. 3), the observation that the limited available data makes it difficult to determine if bisphosphonate treatment is truly protective or reflects the natural history of the disease in less effected patients, and the ineffectiveness of bisphosphonates to prevent mortality in some patients even when instituted early ${ }^{4-7}$.

The overall incidence of GACI is rare, with 200 reported cases in the medical literature ${ }^{8}$ and a disease frequency of one in 391,000 (ref. 9). Although the disease was first described by Bryant and White in 1901 (ref. 10), it was not until 2000 that Rutsch et al. ${ }^{11}$ noted that serum plasma inorganic pyrophosphate $\left(\mathrm{PP}_{\mathrm{i}}\right)$ levels and ectonucleotide pyrophosphatase/phosphodiesterase 1 (ENPP1) enzymatic activity were significantly impaired in GACI patients. ENPP1 (also known as PC-1) is the founding member of the ENPP or NPP family of enzymes, which are characterized by phosphodiesterase activity ${ }^{12}$, and is a type II extracellular membrane bound glycoprotein located on the mineral-depositing matrix vesicles of osteoblasts and chondrocytes, as well as the vascular surface of cerebral capillaries ${ }^{13}$. ENPP1 is the primary source of extracellular $\mathrm{PP}_{\mathrm{i}}$ in the body, and hydrolyzes extracellular ATP into AMP and $\mathrm{PP}_{\mathrm{i}}$ (refs 12,14). $\mathrm{PP}_{\mathrm{i}}$ acts as a potent inhibitor of mineralization, presumably by occupying some of the $P_{i}$ sites on the surface of nascent or growing hydroxyapatite crystals, thereby creating irregularities that slow or terminate crystal growth ${ }^{14,15}$. Rutsch et al. discovered that inactivating mutations in ENPP1 account for $75 \%$ of GACI patients $2,11,16$ and have contributed to recent observations that a sizable fraction of the remaining patients result from inactivating mutations in the ATP dependent membrane transporter ABCC6 (refs 17-22). ABCC6 mutations result in decreased extracellular concentrations of nucleoside triphosphates through an unknown mechanism ${ }^{23}$, thereby limiting ENPP1's metabolism of ATP into extracellular $\mathrm{PP}_{\mathrm{i}}$. The identification of both ENPP1 and ABCC6 inactivating mutations as genetic etiologies for GACI therefore links the same biochemical pathway to unregulated tissue mineralization in both genetic variants of GACI.

Despite the multiple genetic etiologies and multifactorial nature of the expression, progression, and severity of medial wall vascular calcification, we hypothesized that disruption of a

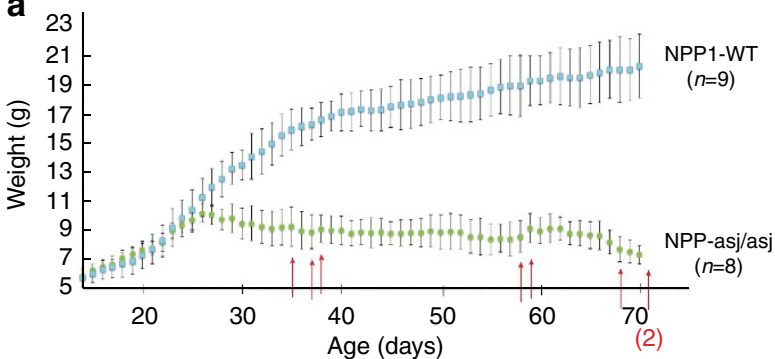

b

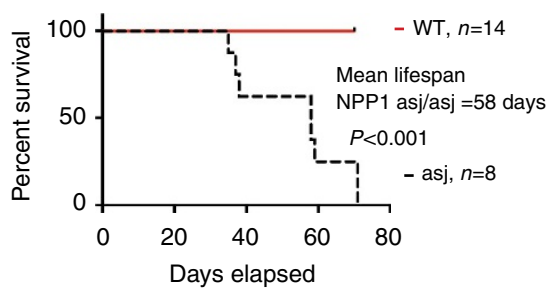

C

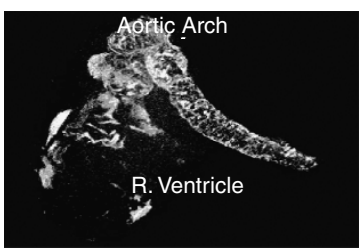

d

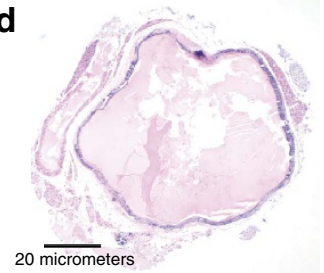

e

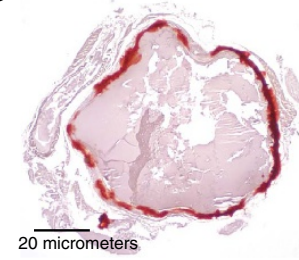

f

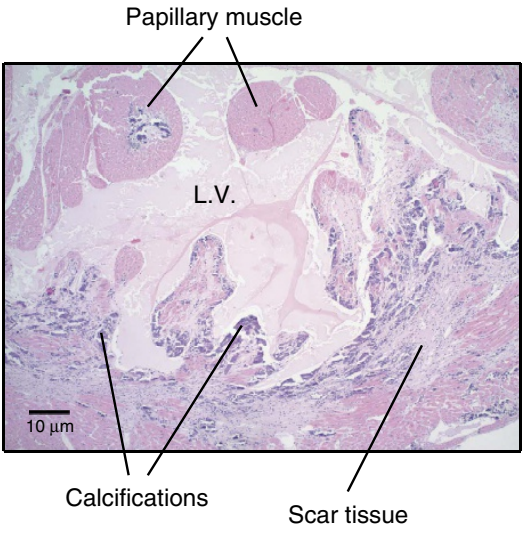

g

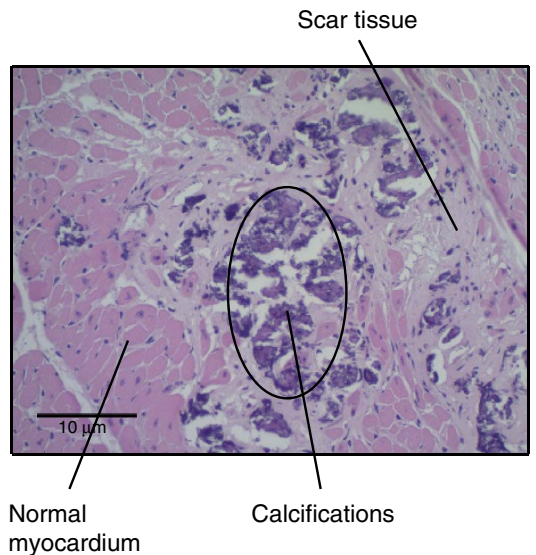

Figure 1 | Natural history study. (a) Daily weights of enpp $7^{\text {wt }}$ (cyan squares, $n=9$ animals) and enpp ${ }^{a s j / a s j}$ mice (green circles, $n=8$ animals) on the acceleration diet in utero over a 70 day period. Mean average weights are plotted with s.d's denoted by error bars. A failure to thrive point is noted in the enpp $7^{a s j / a s j}$ cohort at day 26, when the weights diverge from enpp $7^{\text {wt }}$. Death events are marked with red arrows. (b) Mean survival of enpp $7^{a s j / a s j}$ was 58 days. No deaths were observed in the enpp $1^{\text {wt }}$ cohort. Analysis by log-rank (Mantle-Cox) test yields a $\chi^{2}$ of 15.73 and $P$ value of $<0.0001$. (c) enpp $1^{\text {asj/asj }}$ animals displayed dramatic calcifications in heart and aorta visible on micro-CT scans. (d,e) Histology of enpp ${ }^{\text {asj/asj }}$ mice, aorta (Hematoxylin and Eosin

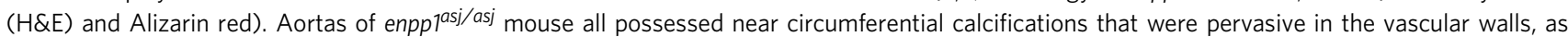
illustrated by Alizarin red staining of the aortas. Scale bar, $20 \mu \mathrm{m}$ (f). Histology of enpp ${ }^{a s j / a s j}$ mice, left ventricle. Extensive calcifications surrounded by scar tissue revealing the presence of repeated, old and healed myocardial infarctions. Scale bar, $10 \mu \mathrm{m}$ (g). Histology of enpp ${ }^{a s j / a s j}$ Mice, Septum (H\&E). More typically, the enpp $1^{a s j / a s j}$ mice displayed small foci of calcifications with surrounding scar tissue as seen here in the myocardial septum, also diagnostic of previous myocardial infarctions. Scale bar, $10 \mu \mathrm{m}$. 


\begin{tabular}{|lcc|}
\hline \multicolumn{3}{|l|}{ Table 1 | Cardiovascular pathology, natural history study. } \\
& WT & asj/asj \\
\hline Calcifications in heart (CT/histology) & $0 / 0$ & $37 \% / 100 \%$ \\
Calcifications in aorta (CT/histology) & $0 / 0$ & $62 \% / 100 \%$ \\
Calcifications in coronary arteries (histology) & $0 / 0$ & $100 \%$ \\
Myocardial infarction (histology) & 0 & $70 \%$ \\
\hline CT, computed tomography; WT, wild-type. & & \\
\hline
\end{tabular}

ENPP1's extracellular purinergic metabolism accounts for the pathologic sequela and mortality associated with GACI and that enzyme replacement therapy with ENPP1 is a tractable therapeutic approach. To test this hypothesis, we employed ENPP1-asj mice (Jackson Laboratory), which carry an inactivating mutation in enpp1 such that homozygotes (enpp $1^{\text {asj/asj }}$ have markedly reduced ENPP1 function. To enhance the disease phenotype, the mice were maintained on the an 'acceleration diet' in utero $^{24,25}$. Here we demonstrate that daily subcutaneous doses of a biologic agent comprising the extracellular domain of ENPP1 fused to the $\mathrm{Fc}$ region of human IgG1 eliminates the vascular calcifications, mortality, myocardial infarctions, and sequela of GACI in enpp1 $1^{a s j / a s j}$ mice, and that this clinical response is accompanied by normalization of serum and tissue $\mathrm{PP}_{\mathrm{i}}$ concentrations.

\section{Results}

Natural history study of GACI in enpp1 ${ }^{a s j / a s j}$ mice. When fed an acceleration diet, the daily weights of enpp $1^{a s j / a s j}$ mice diverged from wild-type (WT) siblings pairs at day 26, when the ENPP1asj/asj mice experienced a 'failure to thrive' event and began to lose weight (Fig. 1a). After day 26 the enpp $1^{a s j / a s j}$ animals displayed progressive stiffness and reductions in physical activity. All of the enpp1 $1^{a s j / a s j}$ animals died between days 35-71, with a median lifespan of 58 days (Fig. 1b). The presence of calcifications in enpp $1^{a s j / a s j}$ and enpp1 $1^{\text {wtj }}$ mice was evaluated via postmortem by micro-computed tomography (CT) scans (Fig. 1c) and histologic sections taken from the heart, aorta and kidneys (Fig. 1d-g). Approximately one-third of the enpp $1^{a s j / a s j}$ mice had visible calcifications in their hearts, and two-thirds had calcifications in their aortas visible by micro-CT imaging (Table 1). These percentages increased to $100 \%$ on histologic examination, which also showed that many of the animals had dramatic nearly circumferential calcifications in their aortic walls (Fig. 1d,e). Histologic examination also revealed that $100 \%$ of the coronary arteries possessed arterial wall calcifications and that $70 \%$ of the animals had focal or confluent areas of myocardial necrosis consistent with myocardial infarction (Fig. 1f,g). Conversely, the enpp1 $1^{w t}$ mice displayed none of these abnormalities. These findings demonstrate that the animal model recapitulates GACI in humans, which is characterized by prominent calcifications of the large and medium sized arteries and a cardiac demise.

Design and characterization of therapeutic. To produce soluble, recombinant ENPP1 for in vivo use, we modified our previous expression construct ${ }^{26}$ by fusing ENPP1 to the Fc domain of IgG1 (hereafter referred to as hENPP1-Fc and mENPP1-Fc for the human and mouse protein isoforms, respectively, Fig. 2b) and expressed the fusion protein in stable mammalian (HEK293) cell lines (Supplementary Note 1). The effect of expressing the hENPP1-Fc in mammalian, as compared to our previous studies in insect cells ${ }^{26}$, altered the Michaelis-Menton kinetics by reducing (tightening) the Michaelis constant $K_{\mathrm{M}}$ for ATP

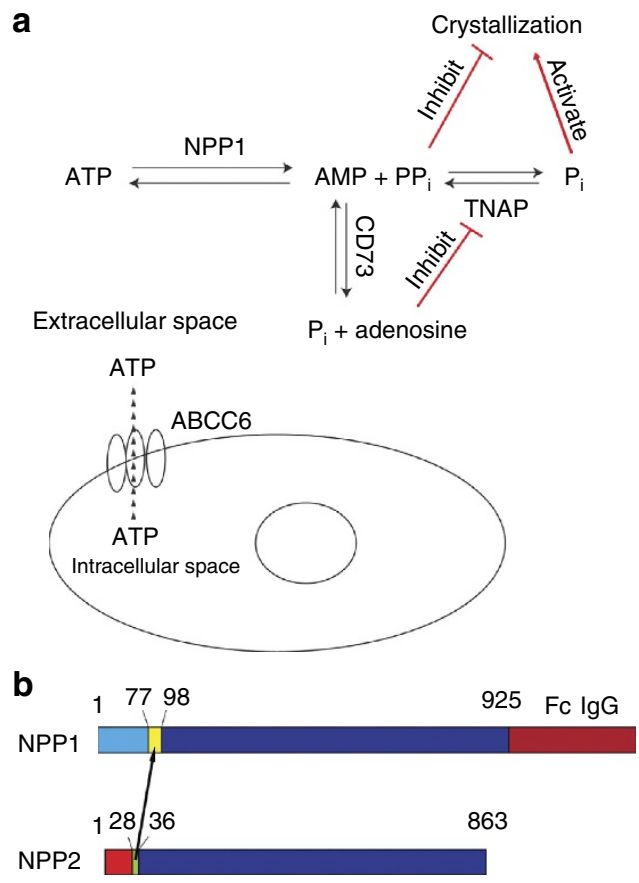

Figure 2 | Metabolic pathways and therapeutic design. (a) Metabolic pathways of interest. ENPP1 converts extracellular ATP into AMP and $\mathrm{PP}_{\mathrm{i}}$ TNAP converts $\mathrm{PP}_{\mathrm{i}}$ into $\mathrm{P}_{\mathrm{i}}$, and CD73 converts $\mathrm{AMP}$ into adenosine and $\mathrm{P}_{\mathrm{i}}$. ABCC6 is a membrane transporter that increases the extracellular concentration of NTP via an indirect unknown mechanism (shown as a dashed line). Loss of function mutations in TNAP result in familial hypophosphatasia. Loss of function mutations in ENPP1 result in $\mathrm{GACl}$, loss of function mutations in $A B C C 6$ result in pseudoxanthomatous elasticum, and loss of function mutations in CD73 results in a disease of arterial and joint calcification termed 'ACDC'. TNAP, tissue-nonspecific alkaline phosphatase. (b) Design of ENPP1 protein therapeutic. To produce a soluble recombinant protein, a segment of the extracellular region of NPP2 containing a furin cleavage site was substituted into ENPP1 (ref. 26) and the Fc portion of IgG1 was appended to the c-terminus.

substrate by over two orders of magnitude, while also reducing (slowing down) the $k_{\text {cat }}$ by a factor of 2-3 (Fig. 3a-c). The altered Michaelis-Menton constants could reflect either the change in expression system from baculovirus-infected insect cells to mammalian cells or the addition of the Fc tag. To differentiate between these two possibilities, we expressed hENPP1 without an Fc tag in mammalian (HEK293) cell lines to directly compare the kinetics of ENPP1 with and without an Fc tag. We found that the kinetic constants of the hNPP1-Fc and hNPP1 enzymes expressed in mammalian cells were essentially identical (Fig. 3d), suggesting that the alteration in kinetic constants was due to the change in expression systems.

To understand the pharmacokinetics of ENPP1-Fc we determined plasma concentrations of drug following a single subcutaneous injection over time. Fifteen mice were administered a single subcutaneous dose of $10 \mathrm{mg} \mathrm{kg}^{-1}$ and blood was collected from tail veins to quantitate ENPP1-Fc in the plasma. The concentration ENPP1-Fc reaches a maximal plasma concentration of $\sim 300 \mathrm{nM}\left(C_{\max }\right)$ within $8 \mathrm{~h}\left(t_{\max }\right)$ and remains elevated at $100 \mathrm{nM}$ for $72 \mathrm{~h}$ after dosing (Fig. 4a). The integral of the plotted concentration-time curve, or area under the curve, is $9 \mu \mathrm{Mh}^{-1}$. Plotting the data as fraction of drug absorbed over time allows for the determination of the elimination $\left(k_{\mathrm{e}}\right)$ and absorption $\left(k_{\mathrm{a}}\right)$ constants by fitting the data to the equation for the total systemic absorption of a drug administered at a 

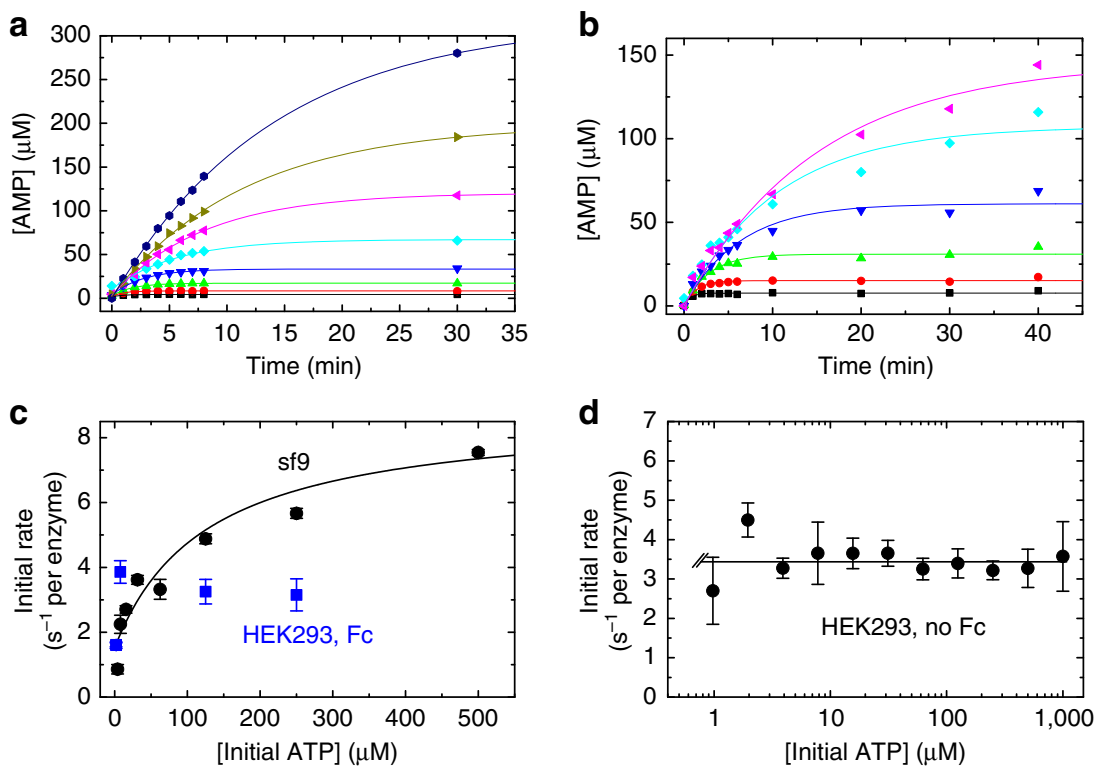

Figure 3 | Steady state kinetics of hENPP1-Fc. Time courses of AMP formation measured by HPLC analysis after addition of (a) $50 \mathrm{nM}$ hNPP1 purified from sf9 cells to (from bottom to top) 3.9 (black), 7.8 (red), 15.6 (green), 31.3 (blue), 62.5 (cyan), 125 (magenta), 250 (dark yellow) and 500 (navy) $\mu$ M ATP or (b) $10 \mathrm{nM}$ hNPP1 from HEK293 cells to (from bottom to top) 7.8 (black), 15.6 (red), 31.3 (green), 62.5 (blue), 125 (cyan) and 250 (magenta) $\mu$ M ATP. The smooth curves though the data are fits obtained by non-linear kinetic time course analysis ${ }^{39}$. (c) Comparison of ENPP1 expressed in insect cells with ENPP1-Fc expressed in mammalian cells. NPP1 (sf9, black circles) is human ENPP1 produced in baculovirus-infected cells while NPP1 (HEK293, Fc and blue squares) is human ENPP1-Fc produced in HEK293 cells. The initial rate of ATP cleavage by ENPP1-Fc from HEK293 cells is essentially the same at [ATP] greater than $7.8 \mu \mathrm{M}$, yielding a $k_{\text {cat }}$ (the average of the rates $\left.\geq 7.8 \mu \mathrm{M}\right)$ of $3.4( \pm 0.4) \mathrm{s}^{-1}$ per enzyme. The initial rate at $2.0 \mu \mathrm{M}$ ATP concentration is about a half of the $k_{\text {cat }}$ value. We therefore estimate a $K_{M} \sim 2 \mu \mathrm{M}$ for ATP hydrolysis by hNPP1-Fc protein. (d) ATP concentration dependence of the initial hydrolysis rate of ENPP1 (no Fc) purified from HEK293 cells. The reaction displays a $k_{\text {cat }}$ of $3.46( \pm 0.44) \mathrm{s}^{-1}$ per enzyme, estimated from the average of all ATP concentrations $\geq 2 \mu \mathrm{M}$. At $1 \mu \mathrm{M}$ initial ATP (the first data point), the hydrolysis rate is slightly less than $k_{\text {cat }}$ values. We therefore estimate a $K_{M}<2 \mu \mathrm{M}$ for ATP hydrolysis by ENPP1 (no Fc) purified from HEK293 cells.

subcutaneous depot at time zero,

$$
F=\frac{k_{\mathrm{a}}}{\left(k_{\mathrm{a}}-k_{\mathrm{e}}\right)}\left[e^{-k_{\mathrm{e}} t}-e^{-k_{\mathrm{a}} t}\right] .
$$

This analysis yield a $k_{\mathrm{e}}=0.107 \pm 0.016 \mathrm{~h}^{-1}$ and a $k_{\mathrm{a}}=0.048 \pm$ $0.008 \mathrm{~h}^{-1}$, which yields an elimination half life $\left(t_{1 / 2}\right)=6.5 \mathrm{~h}$ (Fig. 4b).

The activity of ENPP1-Fc was noted to diminish over a 30 day period when stored at $4{ }^{\circ} \mathrm{C}$, but the enzyme could be frozen at $-80^{\circ} \mathrm{C}$ and retain nearly complete activity on thawing (Fig. 4c). The enzyme was therefore stored as a frozen stock solution after purification until needed. The oligomerization state of ENPP1-Fc at $1 \mu \mathrm{M}$ and $100 \mathrm{nM}$ was determined by size exclusion chromatography coupled with light scattering, refractive index, and absorbance (ultraviolet) detection (SEC-MALLS/RI/UV) ${ }^{27}$, which allows for a determination of the molecular weight (MW) of glycosylated proteins from the relationship of molecular weight and the ratio of laser light scattering, ultraviolet and refractive index (RI) signals in the absence of knowledge of the extend of glycosylation $^{28}$. The results of the SEC-MALLS analysis revealed that the MW of the ENPP1-Fc protein represents a dimer over the concentration range of $100 \mathrm{nM}-1 \mu \mathrm{M}$, with an experimentally determined MW of $274 \pm 38 \mathrm{KDa}$ (Fig. 4d). This agrees well with the calculated MW of $252 \mathrm{KDa}$ for an ENPP1-Fc dimer. The experimental approach also allows for an independent estimation of the glycosylation level of the fusion protein, which was determined to be $\sim 5 \%$ according to the method of Hayashi et al. $^{29}$

Following purification, ENPP1-Fc was dialysed into PBS supplemented with $\mathrm{Zn}$ and $\mathrm{Ca}^{2}+\left(\mathrm{PBS}_{\text {plus }}\right)$ concentrated to between 5 and $7 \mathrm{mg} \mathrm{ml}^{-1}$ and frozen at $-80^{\circ} \mathrm{C}$ in aliquots of
200-500 $\mu \mathrm{l}$. Aliquots were thawed immediately before use, and the specific activity of the solution was adjusted to 31.25 a.u. $\mathrm{ml}^{-1}$ (or $\approx 0.7 \mathrm{mg} \mathrm{ml}^{-1}$ depending on the preparation) by dilution in $\mathrm{PBS}_{\text {plus }}$.

Therapeutic proof of concept in enpp1 $1^{a s j / a s j}$ mice. Dosing was performed according to activity units (a.u.) per kg animal weight to account for variations in specific activity in different protein preparations. The specific activity of the enzyme varied with each protein preparation, and because the clinical response was noted to be highly dependent on enzyme specific activity, we rejected protein preparations with specific activities of $<40$ a.u. $\mathrm{mg}^{-1}$. To establish initial dosing levels for the proof of concept study we performed dose escalation trials in limited numbers of animals (1-2 per dose level). While both the human and mouse version ENPP1 were used in the dose escalation trials, the proof of concept study was performed with the mouse isoform of ENPP1-Fc (mENPP1-Fc). enpp $1^{\text {asj/asj }}$ mice were dosed daily on the fourteenth day of life with subcutaneous injections of mENPP1-Fc and weekly with intra-peritoneal injections of GK 1.5, the latter added to minimize immune rejection of recombinant protein ${ }^{30}$. Subcutaneous doses of mEnpp1-Fc at 500 a.u. $\mathrm{kg}^{-1} \mathrm{qD}$ demonstrated a strong early response in weight with an absence of the observed 'failure to thrive' crisis observed in undosed enpp1 $1^{\text {asj/asj }}$ animals (Supplementary Fig. 1). This dose corresponded to between $6-10 \mathrm{mg} \mathrm{kg}^{-1}$ of ENPP1-Fc, depending on the specific activity of the protein preparation.

On the basis of the results of the dose escalation trials we chose to enrol a cohort of 8 enpp $1^{a s j / a s j}$ animals dosed with mENPP1-Fc at 500 a.u. kg qD and weekly intra-peritoneal injections with GK 
a

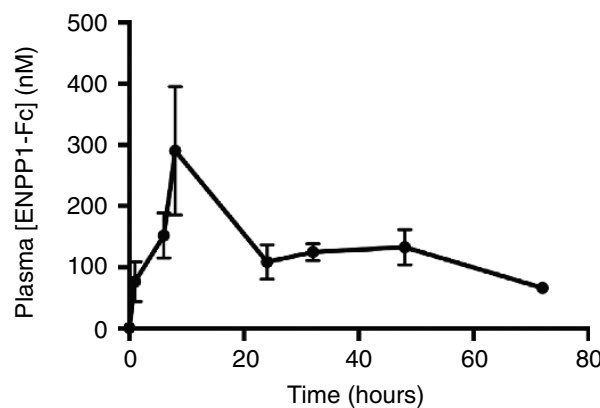

C

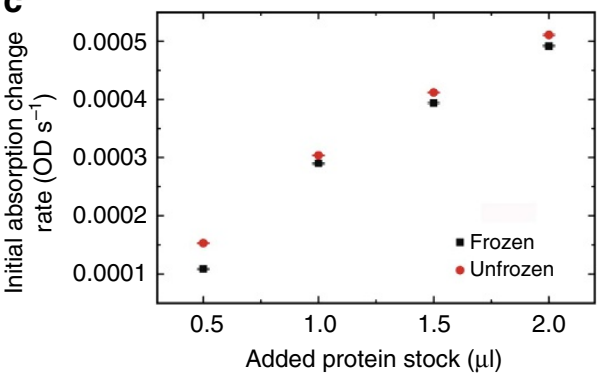

b

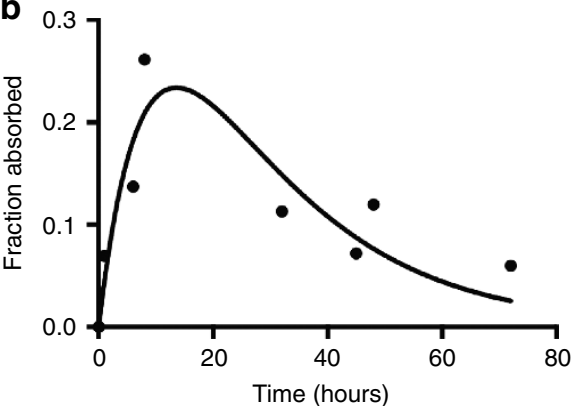

d

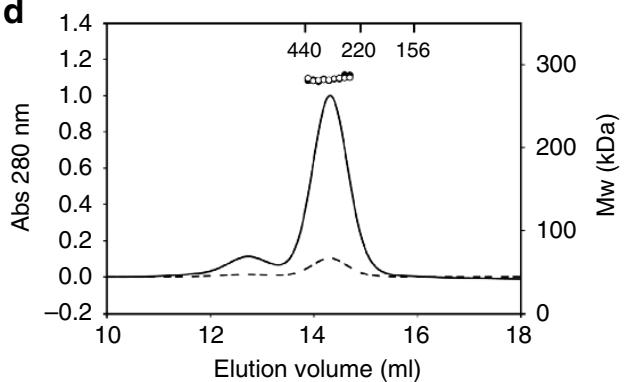

Figure 4 | Characterization of ENPP1-Fc. (a) Pharmacokinetics of absorption and excretion. 15 C57B6 mice were injected with $10 \mathrm{mg} \mathrm{kg}^{-1}$ ENPP1-Fc and blood was collected at the indicated times. The concentration of ENPP1-Fc was estimated from the activity units of enzyme as measured by TMP assay and each data point represents measurement in 5 animals except for time $=0$, which represents 15 animals. The mean value is plotted, and error bars represent s.d. in the measurements. $A C_{\max }$ of $\approx 300 \mathrm{nM}$ is reached at $8 \mathrm{~h}$, and the area under the curve is calculated as $9 \mu \mathrm{Mh}^{-1}$. (b) To derive the pharmacokinetic constants of drug absorption and elimination we plotted the fraction of dosed drug absorbed in the plasma from a single $10 \mathrm{mg} \mathrm{kg}{ }^{-1}$ subcutaneous dose over time and fit the resulting curve with the equation $F=\frac{k_{a}}{\left(k_{a}-k_{e}\right)}\left[e^{-k_{e} t}-e^{-k_{a} t}\right]$ to obtain the elimination and absorption constants $k_{\mathrm{e}}$ and $k_{\mathrm{a}}$, respectively. The resulting curve yielded values for $k_{\mathrm{e}}=0.107 \pm 0.016 \mathrm{~h}^{-1}$ and $k_{\mathrm{a}}=0.048 \pm 0.008 \mathrm{~h}^{-1}$. The goodness of the fit yielded an $R^{2}=0.7573$ and an absolute sum of squares $=0.01$. (c) Stability of ENPP1 therapeutic. ENPP1-Fc Ap3A activity was seen to be stable to freeze-thaw cycle in PBS following storage at $-80^{\circ} \mathrm{C}$. (d) Molecular weight of ENPP1-Fc determined by SEC-MALLS/RI/UV. Weight average molar masses (Mw) are plotted for analyses of ENPP1-Fc protein at various concentrations. Lines correspond to UV traces of the protein eluting from the SEC column monitored at $280 \mathrm{~nm}$ (left axis). Molar masses were recorded every sec across the elution profile (circles; right axis); for clarity only every 20th measurement of molar mass is plotted. ENPP1-Fc protein was analysed in a concentration range from $100 \mathrm{nM}$ (dashed line, empty circles) to $1 \mu \mathrm{M}$ (solid line, filled circles) measured at the apex of the eluting peak. The elution's position of protein standards used for validation of SEC-MALLS/UV/RI performance are marked. The SEC-MALLS/UV/RI analysis yielded MW of $274 \pm 38 \mathrm{KDa}$ with a glycosylation estimate of $0.05 \mathrm{~g}$ of sugars per gram of polypeptide.

1.5 (Fig. 5). We included a control groups (enpp $1^{w t}$ and enpp $\left.1^{a s j / a s j}\right)$ dosed daily with vehicle and weekly with GK 1.5 in an identical manner as the dosed cohort, and the study duration was shortened to 55 days. All 8 treated enpp1 $1^{a s j / a s j}$ animals survived the full 55 days of the trial, with a dramatic clinical response observed in treated animals (Supplementary Movie 1), while the median lifespan of the untreated enpp1 $1^{a s j / a s j}$ animals decreased from 58 to 35 days in the therapeutic trial, perhaps resulting from the weekly intra-peritoneal injections of the GK 1.5 immunosuppressant. The untreated enpp $1^{a s j / a s j}$ animals also all experienced a failure to thrive crisis at day 26 , followed by weight loss and mobility restriction progressing variably to paralysis and death over the next 30 days. All but one untreated enpp1 $1^{a s j / a s j}$ animal expired over the 55 day trial, while in contrast all treated enpp $1^{a s j / a s j}$ mice gained weight comparable to the enpp1 $1^{w t}$ mice and displayed no signs of reduced mobility or stiffness (Supplementary Movie 1).

At the conclusion of the study, $100 \%$ of the enpp $1^{a s j / a s j}$ mice treated with vehicle displayed calcifications in their hearts, aortas and coronary arteries, and $77 \%$ of the animals displayed histologic evidence of myocardial infarction (Table 2). In most cases this took the form of small areas of myocardial cell necrosis and single cell drop out in the vicinity of the cardiac calcifications (Figs $5 \mathrm{~d}$ and $6 \mathrm{f}-\mathrm{h}$ ), but in two animals (22\%) there were large, full thickness myocardial infarctions in the free wall of the right ventricle (Fig. 6c-e). Myocardial fibrosis in the myocardial tissue adjacent to regions of coronary artery calcification was a common finding (Fig. 6g,h), illustrating that ischaemia from coronary artery calcification likely accounts for a substantial burden of the myocardial disease. Some untreated enpp $1^{a s j / a s j}$ animals displayed dramatic calcifications of coronary arteries, heart, ascending and descending aorta (Supplementary Movie 2). In contrast, none of the enpp1 $1^{a s j / a s j}$ animals treated with ENPP1-Fc displayed cardiac, arterial, or aortic calcification on histology or post-mortem micro-CT (Table 2 and Figs 5e, 6b and 7a). Although renal calcifications are not a feature of human GACI, the enpp1 $1^{a s j / a s j}$ mouse model is noted to have calcifications in the kidneys. Similar to previous findings, we noted light calcifications in the kidneys of $\approx 60 \%$ of the WT animals and $100 \%$ of the dosed enpp1 $1^{a s j / a s j}$ mice. The calcifications in these animals were centred in the renal medulla. $100 \%$ of the undosed enpp1 $1^{a s j / a s j}$ animals had heavy, extensive calcifications, centred in the outer medulla, with extension into the renal cortex. In comparison to previous reports, the renal calcifications in the dosed animals seem to approximate renal calcifications seen in the heterozygous enpp ${ }^{W T / a s j}$ animals.

Biomarker response. In addition to survival, daily animal weights, and terminal histology, treatment response was also assessed via post-mortem high-resolution micro-CT scans to image vascular calcifications, plasma $\mathrm{PP}_{\mathrm{i}}$ concentrations, and 


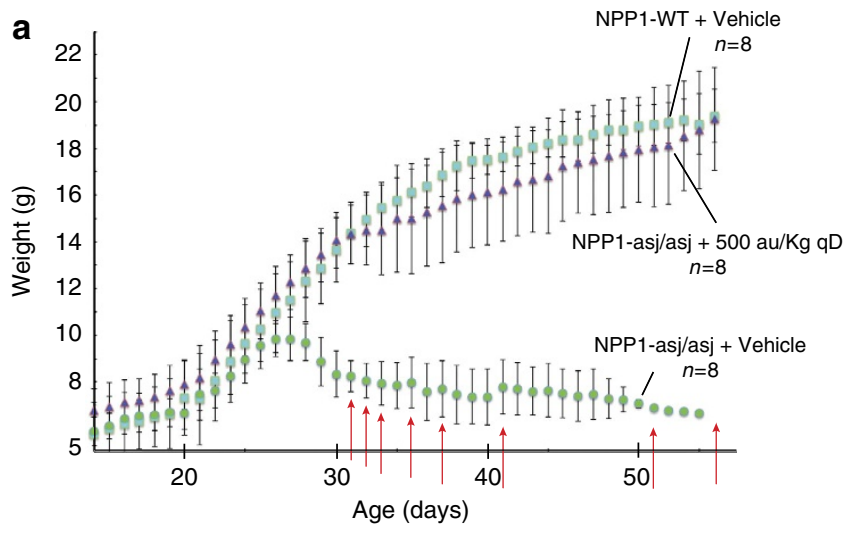

b
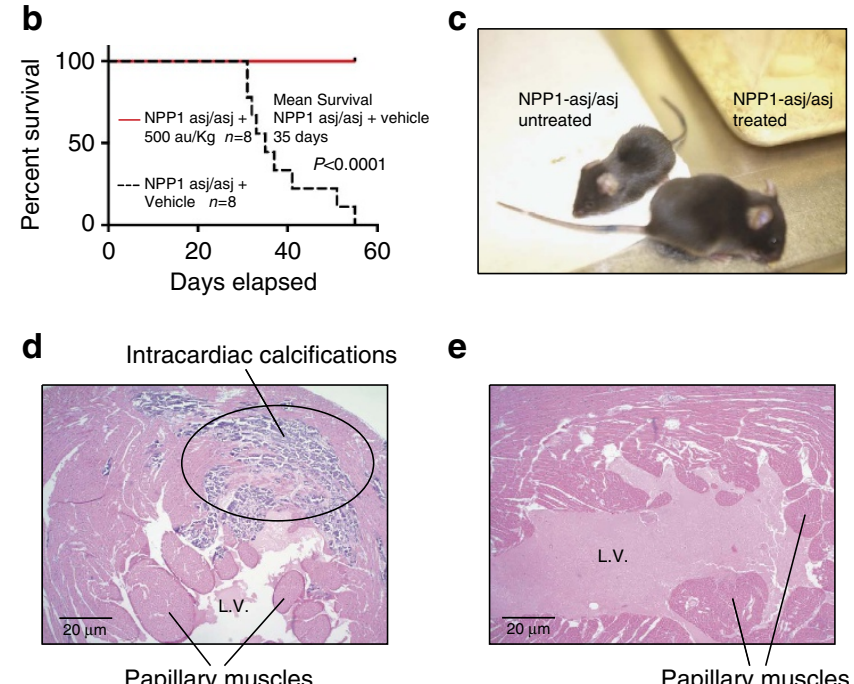

e

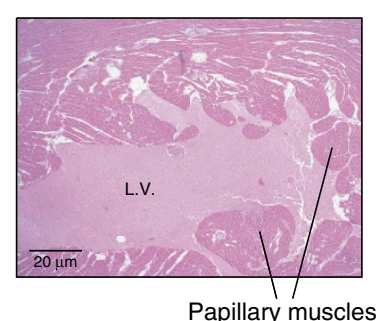

Figure 5 | Proof of Concept Study. (a) Daily animal weights. The mean daily weights of enpp $7^{w t}$ (cyan squares, $n=8$ ), treated enpp ${ }^{\text {asj/asj }}$ (purple triangles, $n=8$ ), and untreated enpp ${ }^{a s j / a s j}$ mice (green circles, $n=8$ ) are plotted with s.d.'s denoted by error bars. Dosing with eNPP1-Fc and weighing commenced on day 14. Treatment consisted of daily injections of $10 \mathrm{mg} \mathrm{kg}^{-1}$ ENPP1-Fc formulated in PBS plus and weekly injections of Gk 1.5.

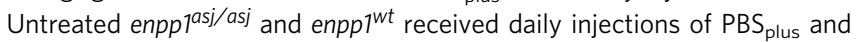
weekly injections of GK 1.5. Deaths in the untreated enpp 1asj/asj $^{\text {cohort are }}$ denoted by red arrows on the day of death. No deaths were noted in the enpp $7^{\text {wt }}$ or the treated enpp $7^{a s j / a s j}$ cohort. (b) Survival curves, proof of concept study. The survival of treated and untreated enpp $1^{a s j / a s j}$ animals are plotted as a solid red line and dashed black line, respectively. Analysis by Log-rank (Mantle-Cox) test yields a $\chi^{2}$ of 13.18 and $P$ value of 0.003 .

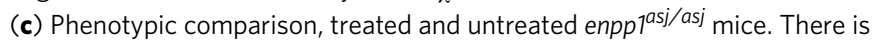
a dramatic size difference in the treated and untreated animals, and a marked difference in the mobility and health of the animals, best seen in Supplementary Movie 1. (d) Left ventricle histology, untreated asj/asj mouse Hematoxylin and Eosin (H\&E), displaying large focus of calcifications and micro-infarctions in the free wall. Scale bar, $20 \mu \mathrm{m}$. (e) Left ventricle histology, treated enpp $1^{a s j / a s j}$ mice (H\&E). None of the treated enpp $1^{a s j / a s j}$ mice displayed abnormal L. ventricular histology. Scale bar, $20 \mu \mathrm{m}$.

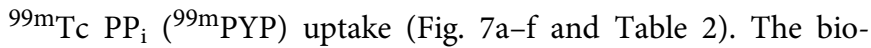
chemical and physiologic response was complete as measured by all of these parameters. None of the WT or treated enpp $1^{\text {asj/asj }}$ animals were noted to possess any vascular calcifications via micro-CT, in contrast to the dramatic calcifications noted in the aortas, coronary arteries, and hearts of the untreated enpp $1^{\text {asj/asj }}$ cohort (Fig. 7a). In addition, serum $\mathrm{PP}_{\mathrm{i}}$ concentrations of treated enpp1 $1^{\text {asj/asj }}$ animals $(\approx 5.2 \mu \mathrm{M})$ were elevated to WT levels
$(4.4 \mu \mathrm{M})$ and significantly above untreated enpp1 $1^{\text {asj/asj }}$ levels $(<0.5 \mu \mathrm{M})$ (Fig. 7b).

$99 \mathrm{~m}$ PYP, an imaging agent typically employed in cardiac imaging and bone remodelling, was used as a marker for treatment response. It is sensitive to areas of unusually high-bone rebuilding activity since it localizes to the surface of hydroxyapatite and then may be taken up by osteoclasts. One would expect increased ${ }^{99 m}$ PYP uptake in animals lacking functional ENPP1 since they have reduced plasma $\left[\mathrm{PP}_{\mathrm{i}}\right]$ and correspondingly elevated rates of mineralization. To test this hypothesis, we performed weekly in vivo ${ }^{99 \mathrm{~m}} \mathrm{PYP}$ imaging in enpp $1^{w t}$ and undosed enpp1 $1^{\text {asj/asj }}$ animals to detect differences in $99 \mathrm{~m} P Y \mathrm{P}$ uptake between the sibling pairs (Fig. $7 \mathrm{c}, \mathrm{d}$ ). We limited analysis of ${ }^{99 m}$ PYP uptake to the head, which is comprised of both enchondral bone (skull) and soft tissue (vibrissae), which are known sites of ectopic calcification in enpp $1^{a s j / a s j}$ mice. This also simplified data analysis as the head does not overlap with internal organs showing transient ${ }^{99 \mathrm{~m} P Y P}$ uptake (such as the bladder, heart and diaphragm) during the $180^{\circ}$ camera rotation that occurs during data collection.

Weekly serial imaging of enpp $1^{w t}$ and untreated enpp1 $1^{a s j / a s j}$ animals demonstrated that, as expected, uptake of ${ }^{99 \mathrm{~m} P Y P}$ in the heads as per cent injected dose was greater in enpp $1^{a s j / a s j}$ animals than in enpp $1^{w t}$ animals, and that changes in $99 \mathrm{~m} P Y \mathrm{P}$ uptake within experimental groups did not vary significantly over the course of the study (Fig. 7c,d). We therefore chose to measure ${ }^{99} \mathrm{~m}$ PYP uptake in treated and untreated enpp1 $1^{a s j / a s j}$ animals at two time points-days $30-35$ and at the completion of the study (days 50-65). Comparison of these experimental groups demonstrates that ENPP1-Fc treatment returned ${ }^{99 m}$ PYP uptake in GACI mice to WT levels (Fig. 7e,f), suggesting that ENPP1-Fc treatment is able to abrogate unregulated tissue, vibrissae and skull mineralization in enpp1 $1^{a s j / a s j}$ mice by raising the extracellular $\mathrm{PP}_{\mathrm{i}}$ concentrations.

Reappearance of calcifications following cessation of dosing. To address questions regarding the reappearance of calcifications following the cessation of dosing, we enrolled two animals in a limited dosing trial in which enpp $1^{a s j / a s j}$ animals were dosed with hENPP1-Fc starting on day 14 and ending on day 27. On day 28 and thereafter the animals were dosed with $\mathrm{PBS}_{\text {plus }}$ and the appearance of vascular calcifications were followed with weekly in vivo CT scans (Fig. 8a). Both animals were free of calcifications until day 64, when one animal developed calcifications in the heart, which were noted on day 79 to progress to the aorta, spleen, kidney, and liver. The second animal developed renal calcifications on day 79. Surprisingly both animals remained alive past day 84 . The limited dosing study demonstrates that calcifications reappear following the cessation of dosing and that treatment in the 14-27 day window significantly extends survival in enpp1 $1^{a s j / a s j}$ animals maintained on the acceleration diet in utero.

\section{Discussion}

Diseases of ectopic tissue calcification range from ultra-rare diseases such as GACI to nearly ubiquitous maladies in the aging population such as hardening of the arteries. The genetic aetiology of human GACI suggests that the lethal arterial calcifications result from impairment of extracellular purinergic metabolism, either through loss of function mutations in ENPP1 or upstream reductions in nucleotide triphosphates metabolized by ENPP1 into extracellular $\mathrm{PP}_{\mathrm{i}}$. Here we demonstrate that daily subcutaneous injections of ENPP1-Fc fusion protein eliminate the mortality, cardiac and arterial calcifications, and other sequela of disease in rodent models of GACI. ENPP1 is the enzyme 
Table 2 | Cardiovascular pathology, proof of concept study.

\begin{tabular}{lccc} 
& WT + Vehicle & asj/asj + vehicle & asj/asj $+\mathbf{m E N P P 1 - F c ~}$ \\
\hline Calcifications heart (CT/Histology) & $0 / 0$ & $55 \% / 100 \%$ & $0 / 0$ \\
Calcifications aorta (CT/Histology) & $0 / 0$ & $66 \% / 100 \%$ & $0 / 0$ \\
Calcifications in coronary arteries (CT/histology) & $0 / 0$ & $43 \% / 100 \%$ & $0 / 0$ \\
Myocardial infarction (Histology) & $0 / 0$ & $77 \%$ & 0 \\
Renal calcifications & $60 \%$ (light) & $100 \%$ (heavy) & $100 \%$ (light) \\
\hline CT, computed tomography; WT, wild-type. & & & \\
\hline
\end{tabular}

responsible for the generation of extracellular $\mathrm{PP}_{\mathrm{i}}$, and we demonstrate that ENPP1-Fc raises plasma pyrophosphate levels from the nearly undetectable levels present in enpp $1^{\text {asj/asj }}$ mice to concentrations comparable to those seen in WT sibling pairs. Our findings suggest that ENPP1-Fc may be effective in other diseases of ectopic calcification in which plasma $\mathrm{PP}_{\mathrm{i}}$ concentrations are decreased.

Extracellular $\mathrm{PP}_{\mathrm{i}}$ is a potent inhibitor of mineralization. ENPP1 is the major producer, and tissue-nonspecific alkaline phosphatase (TNAP) is the primary degrader, of extracellular $\mathrm{PP}_{\mathrm{i}}$ (Fig. 2a). In blood, $\left[\mathrm{PP}_{\mathrm{i}}\right]$ is $\sim 320$ times lower than $\left[\mathrm{P}_{\mathrm{i}}\right]$, therefore small changes in $\left[\mathrm{PP}_{\mathrm{i}}\right]$ have large effects in the $\left[\mathrm{P}_{\mathrm{i}}\right] /\left[\mathrm{PP}_{\mathrm{i}}\right]$ ratio, whereas similar magnitude changes in $\left[\mathrm{P}_{\mathrm{i}}\right]$ would not. If the $\left[\mathrm{P}_{\mathrm{i}}\right] /\left[\mathrm{PP}_{\mathrm{i}}\right]$ ratio is the mechanism governing hydroxyapatite mineralization, as has been proposed, attention should be given to plasma $\left[\mathrm{PP}_{\mathrm{i}}\right]$ in patients suffering from disorders in ectopic mineralization.

The contribution of AMP generation and purinergic signalling to the suppression of vascular calcification is incompletely understood but has been addressed previous studies of enpp $1^{a s j / a s j}$ mice using aortic allografts of WT into enpp $1^{a s j / a s j}$ mice and vice vers $^{31}$. These studies demonstrated that normal levels of extracellular pyrophosphate were sufficient to prevent vascular calcification over the entire surface of a transplanted enpp $1^{a s j / a s j}$ aortic allograft. The suppression of calcification in aortic allografts was throughout the entire length of the allograft with no gradient of suppression of calcification observed. Because purinergic signalling is believed to be autocrine or paracrine in nature (and not systemic), the authors concluded that purinergic signalling was either not important for vascular calcification suppression or was not substantially altered by ENPP1 deficiency. Our observations that enpp $1^{a s j / a s j}$ mice dosed with ENPP1-Fc are free of vascular calcifications and have normal plasma $\mathrm{PP}_{\mathrm{i}}$ concentrations supports the notion that plasma PPi levels may be primarily responsible for suppression of vascular calcification in ENPP1 deficiency.

Reduced plasma $\mathrm{PP}_{\mathrm{i}}$ levels are also present in vascular calcification associated with end stage renal disease (ESRD) ${ }^{31,32}$. One in ten adults suffer from chronic kidney disease (CKD), and it is estimated that $80 \%$ of patients with CKD on dialysis and $47-83 \%$ of patients with CKD not on dialysis possess vascular calcifications compromising their quality of life and endangering their health. Vascular calcifications associated with ESRD contributes to poor outcomes by increasing pulse pressure, causing or exacerbating hypertension, and inducing or intensifying myocardial infarctions and strokes. Most patients with ESRD do not die of renal failure, but from the cardiovascular complications of ESRD, and it is important to note that many very young patients with ESRD on dialysis possess coronary artery calcifications. The histologic subtype of vascular calcification associated with CKD is known as Mönckeburg's sclerosis, which is a form of vessel hardening in which calcium deposits are found in the muscular layers of the medial vascular wall. This form of calcification is histologically distinct from intimal or neo-intimal vascular wall calcification commonly observed in atherosclerosis but identical to the vascular calcifications observed in human GACI patients, and in the rodent models of the disease described herein. The similar pathophysiology of vascular calcification present in GACI and CKD suggests that these disorders may be treated by a common therapeutic.

To this point, the current medical strategies treating ectopic vascular calcification of CKD are typically ineffective and are directed at reducing hyperphosphatemia and minimizing serum calcium concentrations. Continuous intra-peritoneal infusions of exogenous $\mathrm{PP}_{\mathrm{i}}$ substantially inhibits vascular calcifications in rodent models of ESRD, but the rapid hydrolysis of $\mathrm{PP}_{\mathrm{i}}$ in vivo prevents translation of this therapy to the clinic ${ }^{33}$. Attempts treating vascular calcifications in rodent models of ESRD with non-hydrolyzable $\mathrm{PP}_{\mathrm{i}}$ analogues (bisphosphonates) required doses above those known to inhibit bone formation, and the anticipated bone toxicity coupled with a renal mechanism of clearance discourages the use of bisphosphonates as therapeutic agents in $\mathrm{CKD}^{34}$. It appears that we are able to circumvent both the poor pharmacokinetics of $\mathrm{PP}_{\mathrm{i}}$ and the bone toxicity of bisphosphonates by fusing the $\mathrm{PP}_{\mathrm{i}}$ generating enzyme ENPP1 to the $\mathrm{Fc}$ domain of IgG1, and demonstrated that the biologic is effective in GACI. We suspect that it may also be effective in vascular calcification associated with CKD.

\section{Methods}

ENPP1-asj GACI mouse model. Animal care and maintenance were provided through Yale University Animal Resource Center at Yale University (New Haven). All procedures were approved by the Animal Care and Use Committee of Yale University and complied with the US National Institutes of Health guide for the care and use of laboratory animals. Heterozygous enpp1 $1^{a s j /+}$ (genotype C57BL/6J-Enpp $1^{\text {asj } / G r s r J, ~ J a c k s o n ~ L a b o r a t o r y ~ s t o c k ~ n u m b e r ~ 012810) ~ b r e e d i n g ~}$ pairs were maintained on the 'acceleration diet' (TD.00442, Harlan Laboratories, Madison WI) throughout the entire experiment and food and water were delivered ad libitum. The animal colony was housed in pathogen free conditions. All experimental animals were maintained on the acceleration diet in utero through completion of the study. Litters were genotyped on day 8 and weaned at day 21 . Following weaning, sibling pairs were sequentially divided into cohorts as described below and enrolled in experimental trials. Animals were consecutively enrolled in experimental trials without regard to gender, and the gender of the experimental animals was not recorded. On the basis of the trial dosing we estimated that statistically significant survival differences could be determined between dosed and undosed animals using a sample size of eight animals in each experimental group. We used identical breeding pairs throughout the study, and all experimental groups were enrolled sequentially beginning with the enpp $1^{\mathrm{wt}}$ and undosed enpp $1^{\text {asj/asj }}$ cohorts and ending with the dosed enpp1 $1^{a s j / a s j}$ cohort. Enrolment of the dosed and undosed enpp1 $1^{a s j / a s j}$ cohorts spanned 4 months. Once the enrolment of an experimental group began both sexes of the appropriate genotype were consecutively enrolled in an experimental cohort with the exclusion of severely runted animals weighing $<5.5 \mathrm{~g}$ at 14 days of life. Following weaning, all experimental animals were housed with littermates to allow for cooperative grooming and nesting. Experimentalists were not blinded during the study.

ENPP1-Fc design. Human and mouse NPP1 (Human: NCBI accession NP_006199; Mouse: NCBI accession NP_03839) modified to express soluble, recombinant protein as described previously ${ }^{26}$ were fused to $\mathrm{IgG}_{1}$ by subcloning into pFUSE-h $\mathrm{IgG}_{1}-\mathrm{Fcl}$ or pFUSE-m $\mathrm{IgG}_{1}-\mathrm{Fcl}$ plasmids (InvivoGen, San Diego, CA), respectively. The final human protein sequence is listed in Supplementary Fig. 1. 


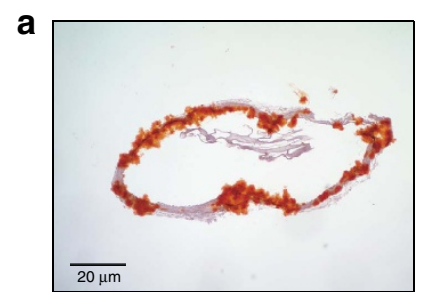

C

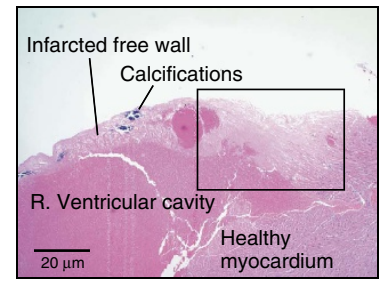

e

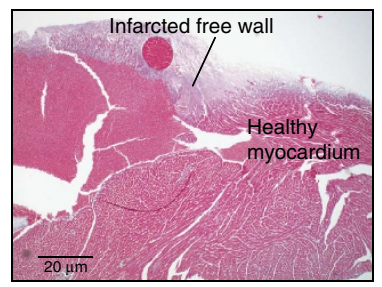

Calcified coronary

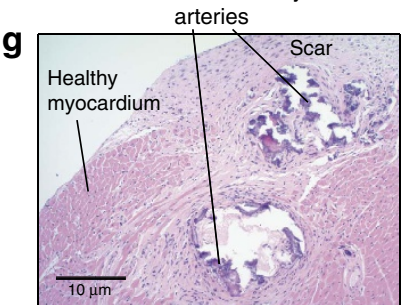

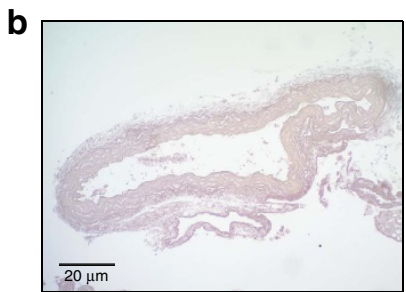
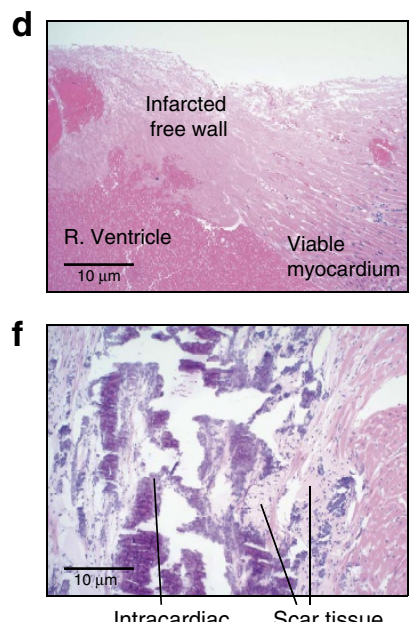
calcations

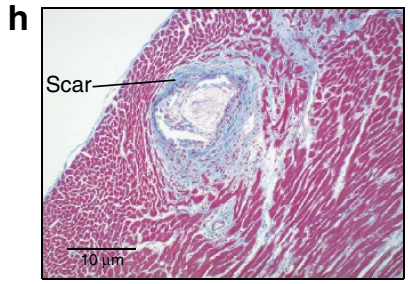

Figure 6 | Representative histology, proof of concept study. (a,b) Aorta (Alizarin red). Untreated enpp ${ }^{a s j / a s j}$ mice displayed nearly circumferential aortic calcifications (a), while treated enpp $1^{\text {asj/asj }}$ mice did not (b). Scale bar, $20 \mu \mathrm{m}$. (c) Untreated enpp $7^{\text {asj/asj }}$ mice, right (R) ventricle Hematoxylin and Eosin (H\&E). Two untreated enpp $1^{a s j / a s j}$ mice had large, confluent, myocardial infarctions in the free wall of the R. ventricle. Scale bar, $20 \mu \mathrm{m}$. All treated enpp ${ }^{a s j / a s j}$ mice displayed normal R. ventricle myocardium (not shown). (d) Untreated enpp ${ }^{a s j / a s j}$ mice, R. ventricle (H\&E) higher power view of the boxed area in panel c. Scale bar, $10 \mu \mathrm{m}$. (e) Untreated enpp $1^{\text {asj/asj }}$ mice, R. ventricle (Trichrome) Trichrome stains of the R.

ventricle in the same animal demonstrates the infarcted free wall. Scale bar, $20 \mu \mathrm{m}$. (f) Untreated enpp $1^{\text {asj } / a s j}$ mice, myocardial septum (H\&E). Nearly all animals (77\%) displayed intracardiac calcifications surrounded by scar tissue, as demonstrated in this animal in the myocardial septum. Scale bar, $10 \mu \mathrm{m}$. (g) Untreated enpp ${ }^{\text {asj/asj }}$ mice, coronary arteries (H\&E). All untreated enpp $1^{a s j / a s j}$ mice had coronary calcifications, with most displaying circumferential calcifications in coronary arteries surrounded by scar tissue, diagnostic of ischaemia and myocardial infarction. Scale bar, $10 \mu \mathrm{m}$.

(h) Untreated enpp $1^{a s j / a s j}$ mice, coronary arteries (Trichrome). Trichrome stains of coronary artery regions of untreated enpp $7^{a s j / a s j}$ mice demonstrates increased fibrosis associated with vascular wall calcifications (blue colour and labelled 'scar'), demonstrating the myocardial injury in the animals. Scale bar, $10 \mu \mathrm{m}$.

Protein production with shaking flasks. Stable transfections of the ENPP1-Fc were established in HEK293 cells under zeocin selection. Briefly, adherent HEK293 cells were adapted for suspension growth by progressive dilution of fetal bovine serum from 10 to $1 \%$ over $5-6$ passages ${ }^{35}$. Zeocin selection $\left(450 \mu \mathrm{g} \mathrm{ml}^{-1}\right)$ was maintained throughout the adaptation process, and cultures were supplemented with $1 \%$ insulin-transferrin-selenium (Mediatech 25-800-CR), and cells were passaged when they reached confluence in $175 \mathrm{~cm}^{2}$ tissue culture flasks. Adapted cells were used to seed liquid culture growths in FreeStyle

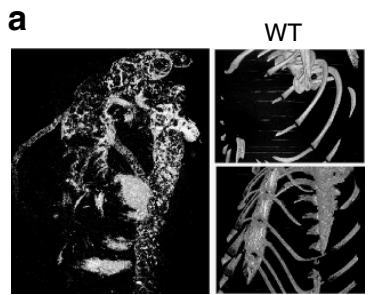

Untreated asj/asj Treated asj/asj

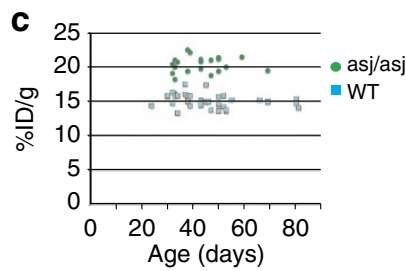

e

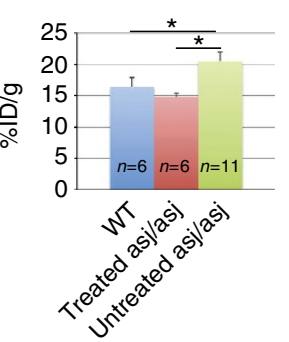

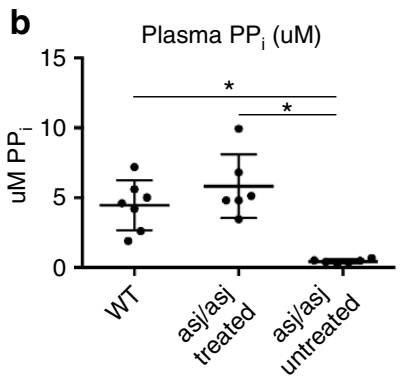

d

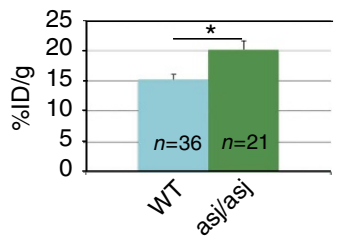

f

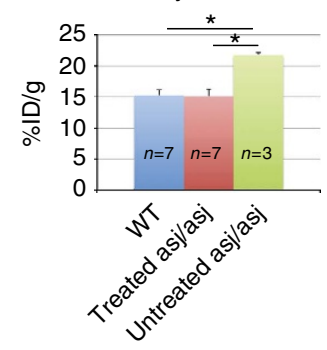

Figure 7 | Biomarkers of disease response. (a) Postmortem highresolution micro-CT scans revealed extensive calcifications in untreated enpp $7^{\text {asj/asj }}$ mice in the hearts, coronary arteries, and ascending and descending aortas, but absolutely no calcifications in these organs in the treated enpp $7^{a s j / a s j}$ cohort or in enpp $7^{\text {wt }}$ mice. For further imaging, Supplementary Movie 2. (b) Plasma $\left[\mathrm{PP}_{\mathrm{i}}\right]$ in enpp $7^{\mathrm{wt}}$ and treated and untreated enpp $1^{\text {asj/asj }}$ animals revealed that treatment with mENPP1-Fc increased $\left[\mathrm{PP}_{\mathrm{i}}\right]$ in enpp ${ }^{\text {asj/asj }}$ mice to $\mathrm{WT}$ levels, and well above the nearly undetectable levels present in untreated enpp $1^{\text {asj/asj }}$ mice. ${ }^{\star} P<0.0015$, Students two-tailed $t$-test. (c,d) Per cent uptake of injected $99 \mathrm{mPYP}$ in heads of WT and asj/asj animals. The per cent uptake of ${ }^{99 m P Y P}$ in heads of animals in the natural history study were recorded weekly in the WT and asj/asj animals on the acceleration diet, demonstrating that $99 \mathrm{mPYP}$ uptake remains nearly constant over an 80 day period following birth, but differs markedly between the two experimental groups. (d) In the natural history study, the average $99 \mathrm{mPYP}$ uptake in heads of enpp $7^{\text {wt }}$ animals was around $15 \%$ of injected dose over the 80 day period, while the PYP uptake in enpp ${ }^{\text {asj } / a s j}$ animals was around $20 \%{ }^{\star} P<0.001$, Students two-tailed $t$-test. $(\mathbf{e}, \mathbf{f}){ }^{99 \mathrm{~m} P Y P}$ uptake. The per cent $99 \mathrm{mPYP}$ uptake in the heads of all experimental groups was recorded in the middle of the study (days 30-35, in $\mathbf{e}$ ) and at the end of the study (days 50-65, in f). enpp $7^{\mathrm{wt}}$ and treated enpp $7^{a s j / a s j}$ animals had per cent uptake in the skulls around $15 \%$, while the untreated enpp $1^{\text {asj/asj }}$ cohort was at or above $20 \%$. ${ }^{\star} P<0.001$, Students two-tailed $t$-test.

medium (Gibco, Waltham MA) in shaker flasks at $37^{\circ} \mathrm{F}$ and $5 \% \mathrm{CO}_{2}$, agitated at 120 r.p.m. with high humidity. Cell density in liquid culure was maintained between 0.5 and $2.5 \times 10^{6}$ cells per $\mathrm{ml}$ and zeocin selection was maintained in liquid culture at $450 \mu \mathrm{g} \mathrm{ml}^{-1}$ until the cells reached a volume of 41 in liquid culture, and then reduced to $225 \mu \mathrm{g} \mathrm{ml}^{-1}$ thereafter. The culture was gradually expanded to 81 and then maintained for another 12 days to accumulate extracellular protein. During the maintenance phase, cultures were supplemented with CD EfficientFeed C AGT (Gibco \#A13275-05) to enhance protein production.

Protein production with bioreactor. Cells were propagated in a 101 bioreactor equipped with dissolved oxygen and $\mathrm{pH}$ control. Dissolved oxygen was kept at 


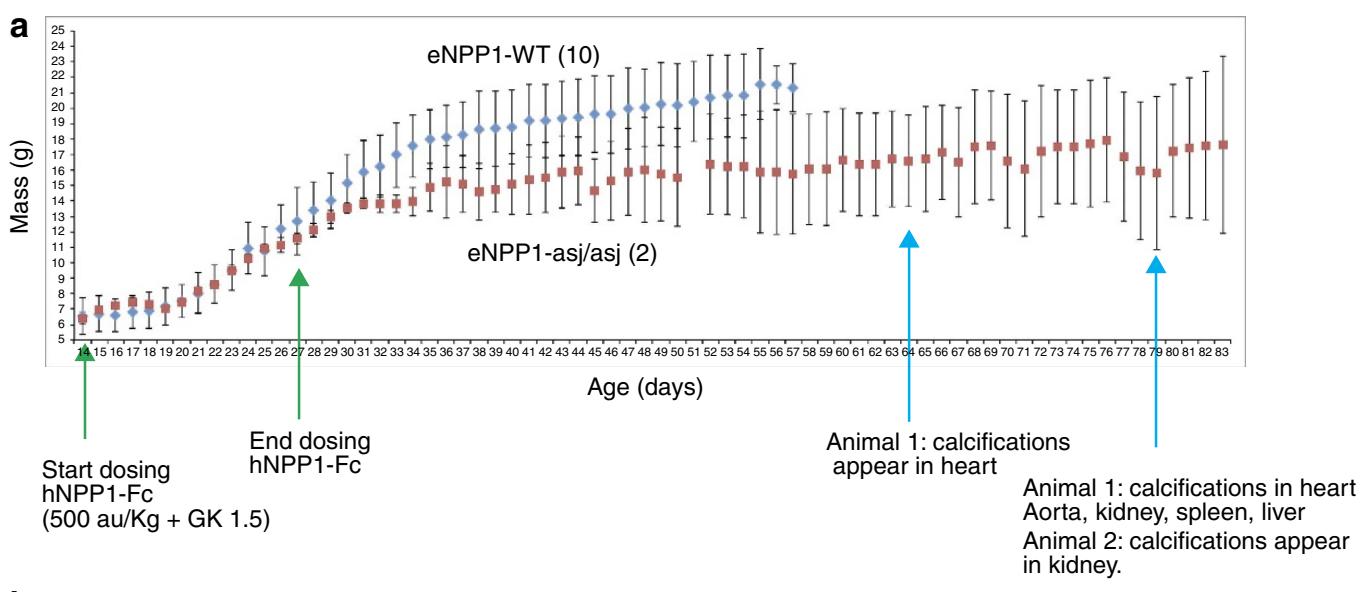

b

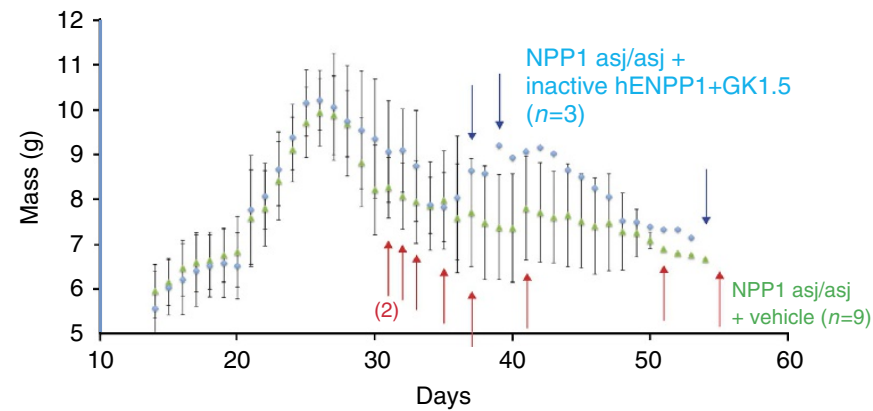

Figure 8 | Limited dosing study. (a) To determine if calcifications reappear following cessation of dosing, two enpp $7^{\text {asj/asj }}$ animals

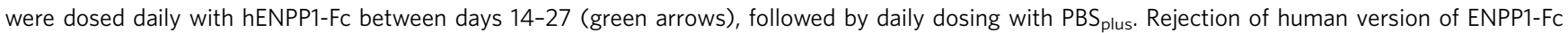
(hENPP1-Fc) was suppressed during the limited dosing period with weekly doses of GK 1.5. The average daily weights are of enpp $7^{\text {wt }}$ (blue triangles, $n=10$ ) and enpp $1^{a s j / a s j}$ (red squares, $n=2$ ) mice are plotted with the error bars denoting s.d.'s. The dosed enpp $1^{a s j / a s j}$ animals were followed for reappearance of vascular and organ calcifications by weekly in vivo CT scans. Calcifications in both animals were eventually observed (cyan arrows). One animal developed calcifications in the heart on day 64, which progressed to the aorta, liver, kidney and spleen by day 79 . The second animal developed renal calcifications on day 79. (b) Negative control experiment. To demonstrate that ENPP1-Fc enzyme activity is essential for therapeutic effect, and that weekly GK 1.5

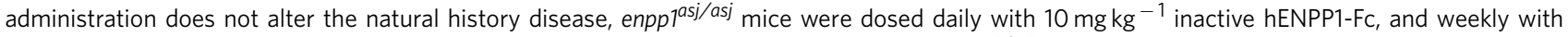
GK 1.5 (blue diamonds, $n=3$ ). The average daily weights are plotted compared with enpp $1^{a s j / a s j}$ mice dosed with vehicle-daily PBS plus and weekly $\mathrm{GK}$ 1.5-(green triangles, $n=9$ ) and the error bars denote s.d.'s. All three enpp ${ }^{\text {asj} / a s j ~ m i c e ~ d o s e d ~ w i t h ~ i n a c t i v e ~ E N P P 1-F c ~ e x p e r i e n c e d ~ a ~ d r o p ~ i n ~ w e i g h t ~ a n d ~}$ mortality (deaths denoted by blue arrows) similar to enpp ${ }^{\text {asj/asj }}$ mice dosed with vehicle (deaths denoted by red arrows), demonstrating that neither inactive ENPP1-Fc nor GK 1.5 extends survival.

$40 \%$ air saturation by supplying the culture with mixture of air and oxygen not exceeding 31 minute at an agitation rate of $80 \mathrm{RPM}$. $\mathrm{pH}$ was controlled at 7.4 by sparging $\mathrm{CO} 2$ when the $\mathrm{pH}$ was higher than 7.4. Culture growth was followed by measuring cell number, cell viability, glucose and lactate concentrations. Final yields for both methods of production were $\sim 5 \mathrm{mg}$ of purified ENPP1-Fc per liter of culture.

Protein purification. The liquid cultures were centrifuged at $4,300 \mathrm{~g}$ for $15 \mathrm{~min}$ and the supernatants were filtered through a $0.2 \mu \mathrm{m}$ membrane and concentrated via tangential low using a Pellicon $30.11 \mathrm{~m}^{2}$ Ultracell $30 \mathrm{kD}$ cassette (Millipore, Billerica MA). The concentrated supernatant was loaded onto a protein-A column, then washed using $50 \mathrm{mM}$ Tris $\mathrm{pH} 8,150 \mathrm{mM} \mathrm{NaCl}_{2}, 1 \mathrm{mM} \mathrm{ZnCl}_{2}$ and $1 \mathrm{mM}$ $\mathrm{CaCl}_{2}$. The recombinant protein was eluted using Elution Buffer $(150 \mathrm{mM}$ Sodium Citrate; $\mathrm{pH}=4.3,150 \mathrm{mM} \mathrm{NaCl}_{2}, 1 \mathrm{mM} \mathrm{ZnCl}_{2}$ and $1 \mathrm{mM} \mathrm{CaCl}_{2}$ ), then immediately neutralized using a 1/10th volume of $1 \mathrm{M}$ Tris $\mathrm{pH} 9.2,150 \mathrm{mM} \mathrm{NaCl}$, $3 \mathrm{mM} \mathrm{ZnCl}_{2}$ and $3 \mathrm{mM} \mathrm{CaCl}_{2}$. Fractions containing enzymatic activity were pooled and dialysed against $\mathrm{PBS}_{\text {plus }}$ buffer $(1 \times$ PBS buffer $\mathrm{pH} 7.4,11 \mathrm{uM} \mathrm{ZnCl} 2,20 \mathrm{uM}$ $\mathrm{CaCl}_{2}$ ), then concentrated to $\sim 6 \mathrm{mg} \mathrm{ml}^{-1}$, distributed into small aliquots and stored at $-80^{\circ} \mathrm{C}$. Resulting protein samples were then tested with Pierce LAL Chromogenic Endotoxin Quantitation Kit (cat. 88282) to verify that all were free of endotoxin.

Enzymology. The steady state hydrolysis of ATP by human NPP1 was determined by high performance liquid chromatography (HPLC; refs 26,36). Briefly, enzyme reactions were started by addition of 10 or $50 \mathrm{nM} \mathrm{NPP1}$ to varying concentrations of ATP in the reaction buffer containing $20 \mathrm{mM}$ Tris, pH 7.4, $150 \mathrm{mM} \mathrm{NaCl}, 4.5$ $\mathrm{KCl}, 14 \mathrm{uM} \mathrm{ZnCl} 2,1 \mathrm{mM} \mathrm{MgCl} 2$ and $1 \mathrm{mM} \mathrm{CaCl} 2$. At various time points, $50 \mu \mathrm{l}$ reaction solution was removed and quenched with an equal volume of $3 \mathrm{M}$ formic acid. The quenched reaction solution was loaded on a C-18 $(5 \mu \mathrm{m} 250 \times 4.6 \mathrm{~mm})$ column (Higgins Analytical) equilibrated in $15 \mathrm{mM}$ ammonium acetate ( $\mathrm{pH}$ 6.0) solution and eluted with a $0-20 \%$ methanol gradient. Substrate and products were monitored by ultraviolet absorbance at $259 \mathrm{~nm}$ and quantified according to the integration of their correspondent peaks and standard curves.

Size exclusion chromatography coupled with static laser light scattering. The light scattering data were collected using a Superose 6, 10/30, HR Size Exclusion Chromatography (SEC) column (GE Healthcare, Piscataway, NJ), connected to high performance liquid chromatography system (HPLC), Agilent 1200, (Agilent Technologies, Wilmington, DE) equipped with an autosampler. The elution from SEC was monitored by a photodiode array (PDA) UV/VIS detector, UV, (Agilent Technologies, Wilmington, DE), differential refractometer, RI, (OPTI-Lab rEx Wyatt Technology, Santa Barbara, CA), static and dynamic, multiangle laser light scattering (LS) detector (HELEOS II with QELS capability, Wyatt Technology, Santa Barbara, CA). The SEC-MALLS/UV/RI system was equilibrated in PBSplus buffer at the flow rate of $0.3 \mathrm{ml} / \mathrm{min}$. Two software packages were used for data collection and analysis: the Chemstation software (Agilent Technologies, Wilmington, DE) controlled the HPLC operation and data collection from the multi-wavelength ultraviolet /VIS detector, while the ASTRA software (Wyatt Corp., Santa Barbara, CA) collected data from the refractive index detector, the light scattering detectors, and recorded the ultraviolet trace from the PDA detector. The weight average molecular weights, $\mathrm{Mw}$, were determined across the entire elution profile in the intervals of $1 \mathrm{~s}$ from static light scattering (LS) measurement using 'three detector approach'27-29.

Vehicle. Mouse ENPP1-Fc (mENPP1-Fc) was formulated in vehicle such that the volume of vehicle delivered was $16 \mu$ l vehicle per gram of body weight. Vehicle consisted of americanBio 10X PBS (Stock\# AB11072) diluted to $1 \times$ with endotoxin free water and supplemented with $14 \mu \mathrm{M} \mathrm{CaCl}$ and $14 \mu \mathrm{M} \mathrm{ZnCl}_{2}$. 
Dosing. Animals in the proof of concept study (Figs 5-7) were dosed either with vehicle or with mouse ENPP1-Fc (mENPP1-Fc) formulated in vehicle. Mice were dosed with daily subcutaneous injections starting on day 14 at dose levels of 500 a.u. $\mathrm{kg}^{-1}$ mENPP1-Fc. Animals in the limited dosing study (Fig. 8a) were dosed with human ENPP1-Fc (hENPP1-Fc) formulated in vehicle beginning on the fourteenth day of life and ending on the twenty-seventh day of life. To tolerize the mice to human protein, the mice were dosed intraperitoneally with $75 \mu \mathrm{g}$ of GK 1.5 (eBioscience, San Diego, CA) on the thirteenth day of life, and $50 \mu$ g of GK 1.5 on the twentieth day of life. Between days 28 and 83 the mice received vehicle. Inactive hENPP1-Fc protein (Fig. 8b) was generated by exposure to EDTA. The specific activity hENPP1-Fc following EDTA exposure was $<20$ a.u. $\mathrm{mg}^{-1}$, or $<50 \%$ of the activity of native protein.

Clearance rate of ENPP1-Fc. Briefly, 15 male C57BI/6J mice aged 8 weeks or older were administered a single subcutaneous dose of $10 \mathrm{mg} \mathrm{kg}^{-1}$ of mENPP1-Fc. Blood was collected from tail veins into heparin-containing tubes before the injection and at different time points post injection. Mice were divided into three groups for blood collection: (1) $1 \mathrm{~h}, 8 \mathrm{~h}, 48 \mathrm{~h}, 96 \mathrm{~h}$. (2). $3 \mathrm{~h}, 24 \mathrm{~h}, 45 \mathrm{~h}$ and $72 \mathrm{~h}$. ( 3 ). $6 \mathrm{~h}$ and $32 \mathrm{~h}$. Enpp 1 activity in plasma were measured with pNP-TMP assay in the following buffer: $100 \mathrm{mM}$ Tris $\cdot \mathrm{HCl}(\mathrm{pH} \mathrm{9.0)}, 500 \mathrm{mM} \mathrm{NaCl}, 5 \mathrm{mM} \mathrm{MgCl} 2,0.05 \%$ (vol/vol) Triton X-100 and $4 \mathrm{mM}$ pNp-TMP. Plasma activity units were converted into protein mass using an empirically determined conversion factor of 0.332 units per $\mu \mathrm{g}$ protein. To derive plasma concentrations and fraction of subcutaneous drug absorbed into plasma, the total blood volume of each mouse was estimated at $1.5 \mathrm{ml}$. Clearance rate constants were derived as detailed in the text.

Definition of activity unit. Animals were dosed according to total activity of enzyme delivered rather than concentration of enzyme to account for varying activity among batches of enzyme used. One activity unit ( 1 a.u.) is defined as $\mathrm{pM}$ of pNP-TMP substrate hydrolyzed $\mathrm{min}^{-1} \mathrm{mg}^{-1}$ enzyme. The activity assay was performed in a buffer consisting of $50 \mathrm{mM}$ Tris $\mathrm{pH} 9,150 \mathrm{mM} \mathrm{NaCl}, 0.1 \mathrm{mM} \mathrm{ZnCl}$, $0.1 \mathrm{mM} \mathrm{CaCl}_{2}, 0.1 \mathrm{mM} \mathrm{MgCl}$. The activity of acceptable protein preparations varied between 40 and 43 a.u. $\mathrm{mg}^{-1}$, and preparations with $<40$ a.u. $\mathrm{mg}^{-1}$ were discarded. A dose of 500 a.u. $\mathrm{kg}^{-1}$ corresponds to between 6 and $10 \mathrm{mg} \mathrm{kg}^{-1}$, depending on the specific activity of the protein preparation.

Quantification of plasma $\mathbf{P P}_{\mathbf{i}}$. Animals were terminally bled retro-orbitally using heparinized, micropipets, and the blood was immediately dispensed into heparintreated eppendorf tubes and placed on wet ice. The samples were spun in a $4{ }^{\circ} \mathrm{C}$ pre-cooled microcentrifuge at 4,000 r.p.m. for $5 \mathrm{~min}$, and plasma was collected and diluted in one volume of $50 \mathrm{mM}$ Tris-Acetate $\mathrm{pH}=8.0$. Plasma was then filtered through a $300 \mathrm{KDa}$ membrane via ultracentrifugation (NanoSep $300 \mathrm{~K}$, Pall Corp., Ann Arbour, MI) and frozen at $-80^{\circ} \mathrm{C}$. Pyrophosphate was quantitated using standard three-step enzymatic assays using uridine $5^{\prime}$ diphospho $\left[{ }^{14} \mathrm{C}\right]$ glucose to record the reaction product, uridine 5 diphospho $\left[{ }^{14} \mathrm{C}\right]$ gluconic acid ${ }^{37}$. Briefly, a reaction mixture $(100 \mu \mathrm{l})$ containing $5 \mathrm{mM} \mathrm{MgCl} 2,90 \mathrm{mM} \mathrm{KCL}, 63 \mathrm{mM}$ Tris-HCL (pH 7.6), $1 \mathrm{nmol} \mathrm{NADP}+, 2 \mathrm{nmol}$ glucose 1,6-diphosphate, $400 \mathrm{pmol}$ uridine $5^{\prime}$-diphosphoglucose, $0.02 \mu \mathrm{Ci}$ uridine $5^{\prime}$ diphospho $\left[{ }^{14} \mathrm{C}\right]$ glucose, 0.25 units of uridine $5^{\prime}$-diphosphoglucose pyrophosphorylase, 0.25 units of phosphoglucose mutase, 0.5 units of glucose 6-phosphate dehydrogenase, and inorganic pyrophosphate $(50-200 \mathrm{pmol})$ is incubated for $30 \mathrm{~min}$ at $37^{\circ} \mathrm{C}$. The reaction is terminated by the addition of $200 \mu \mathrm{l}$ of $2 \%$ charcoal well suspended in water. The mixture is kept on ice, vortexed three times over $15 \mathrm{~min}$ and clarified by centrifugation for $5 \mathrm{~min}$. An aliquote of $200 \mu \mathrm{l}$ of supernatant is then counted in scintillation solution.

In vivo ${ }^{99 \mathrm{~m}} \mathrm{PYP}$ imaging. The bone imaging agent ${ }^{99 \mathrm{~m}} \mathrm{Tc}$-pyrophosphate (Pharmalucence, Inc) was evaluated in cohorts of animals using a preclinical microSPECT/CT hybrid imaging system with dual $1 \mathrm{~mm}$ pinhole collimators (X-SPECT, Gamma Medica-Ideas) $^{38}$. Each animal was injected intraperitoneally with $2-5 \mathrm{mCi}$ of the radiolabelled tracer and imaged $1-1.5 \mathrm{~h}$ after injection. A CT scan $(512$ projections at $50 \mathrm{kVp}, 800 \mathrm{uA}$ and a magnification factor of 1.25) was acquired for anatomical co-localization with the SPECT image. The SPECT imaging was acquired with $180^{\circ}$ per collimator head in a counter-clockwise rotation, 32 projections, $60 \mathrm{~s}$ per projection with an ROR of $7.0 \mathrm{~cm}$, FOV of $8.95 \mathrm{~cm}$ and an energy window of $140 \mathrm{keV} \pm 20$. CT images were reconstructed with the FLEX X-O CT software (Gamma Medica-Ideas) using a filtered back-projection algorithm. SPECT images were reconstructed using the FLEX SPECT software (5 iterations, 4 subsets) and subsequently fused with the CT images and analysed using the AMIRA software and offline in-house script. Data were corrected for decay and injected dose to achieve \% injected dose.

Quantification of ${ }^{99 m}$ PYP uptake. For the ${ }^{99 m}$ PYP murine scans, the animals were imaged two hours postinjection. The resulting SPECT scans were imported into NIH's ImageJ image processing software and regions of interest were drawn around each animal's head (target organ) and whole body. Per cent injected activity (PIA), often referred to as 'per cent injected dose' was calculated by comparing the ratio of counts in the head to the counts in the whole body, and expressed as per cent injected dose to give a measure as of the affinity with which the radiotracer is taken up by the region of interest (head). The total counts in each scan were taken as the whole body measure of injected dose.

\section{References}

1. Moran, J. J. Idiopathic arterial calcification of infancy: a clinicopathologic study. Pathol. Annu. 10, 393-417 (1975).

2. Rutsch, F. et al. Hypophosphatemia, hyperphosphaturia, and bisphosphonate treatment are associated with survival beyond infancy in generalized arterial calcification of infancy. Circ. Cardiovasc. Genet. 1, 133-140 (2008).

3. Otero, J. E. et al. Severe skeletal toxicity from protracted etidronate therapy for generalized arterial calcification of infancy. J. Bone Miner. Res. 28, 419-430 (2013).

4. Stuart, G., Wren, C. \& Bain, H. Idiopathic infantile arterial calcification in two siblings: failure of treatment with diphosphonate. Br. Heart J. 64, 156-159 (1990).

5. Stuart, A. G. Idiopathic arterial calcification of infancy and pyrophosphate deficiency. J. Pediatr. 123, 170-171 (1993).

6. Galletti, S. et al. Generalized Arterial Calcification of Infancy: Fatal Clinical Course Associated with a Novel Mutation in ENPP1. JIMD Rep. 1, 23-27 (2011).

7. Kalal, I. G., Seetha, D., Panda, A., Nitschke, Y. \& Rutsch, F. Molecular diagnosis of generalized arterial calcification of infancy (GACI). J. Cardiovasc. Dis. Res. 3, 150-154 (2012).

8. Chong, C. R. \& Hutchins, G. M. Idiopathic infantile arterial calcification: the spectrum of clinical presentations. Pediatr. Dev. Pathol. 11, 405-415 (2008).

9. Ferreira, C., Ziegler, S. \& Gahl, W. in GeneReviews ${ }^{\circledR}$ (eds Paragon, R. A. et al.) 34 (University of Washington, 2014).

10. Bryant, J. \& White, W. A case of calcification of the arteries and obliterative endarteritis, associated with hydronephrosis, in a child aged six months. Guy's Hosp Rep. 55, 17-28 (1901).

11. Rutsch, F. et al. PC-1 nucleoside triphosphate pyrophosphohydrolase deficiency in idiopathic infantile arterial calcification. Am. J. Pathol. 158, 543-554 (2001)

12. Bollen, M., Gijsbers, R., Ceulemans, H., Stalmans, W. \& Stefan, C. Nucleotide pyrophosphatases/phosphodiesterases on the move. Crit. Rev. Biochem. Mol. Biol. 35, 393-432 (2000).

13. Harahap, A. R. \& Goding, J. W. Distribution of the murine plasma cell antigen PC-1 in non-lymphoid tissues. J. Immunol. 141, 2317-2320 (1988).

14. Terkeltaub, R. Physiologic and pathologic functions of the NPP nucleotide pyrophosphatase/phosphodiesterase family focusing on NPP1 in calcification. Purinergic Signal. 2, 371-377 (2006).

15. Addison, W. N., Azari, F., Sorensen, E. S., Kaartinen, M. T. \& McKee, M. D. Pyrophosphate inhibits mineralization of osteoblast cultures by binding to mineral, up-regulating osteopontin, and inhibiting alkaline phosphatase activity. J. Biol. Chem. 282, 15872-15883 (2007).

16. Rutsch, F. et al. Mutations in ENPP1 are associated with 'idiopathic' infantile arterial calcification. Nat. Genet. 34, 379-381 (2003).

17. Sakata, S., Su, J. C., Robertson, S., Yin, M. \& Chow, C. W. Varied presentation of pseudoxanthoma elasticum in a family. J. Paediatr.Child H. 42, 817-820 (2006).

18. Le Boulanger, G. et al. An unusual severe vascular case of pseudoxanthoma elasticum presenting as generalized arterial calcification of infancy. Am. J. Med. Genet. A 152A, 118-123 (2010).

19. Bertrand, J. et al. Decreased levels of nucleotide pyrophosphatase phosphodiesterase 1 are associated with cartilage calcification in osteoarthritis and trigger osteoarthritic changes in mice. Ann. Rheum. Dis. 71, 1249-1253 (2012).

20. Li, Q., Schumacher, W., Jablonski, D., Siegel, D. \& Uitto, J. Cutaneous features of pseudoxanthoma elasticum in a patient with generalized arterial calcification of infancy due to a homozygous missense mutation in the ENPP1 gene. Br. J. Dermatol. 166, 1107-1111 (2012).

21. Li, Q. et al. Mutations in the ABCC6 gene as a cause of generalized arterial calcification of infancy: genotypic overlap with pseudoxanthoma elasticum. J. Invest. Dermatol. 134, 658-665 (2014).

22. Nitschke, Y. et al. Generalized arterial calcification of infancy and pseudoxanthoma elasticum can be caused by mutations in either ENPP1 or ABCC6. Am. J. Hum. Genet. 90, 25-39 (2012).

23. Jansen, R. S. et al. ABCC6 prevents ectopic mineralization seen in pseudoxanthoma elasticum by inducing cellular nucleotide release. Proc. Natl Acad. Sci. USA 110, 20206-20211 (2013).

24. Li, Q. et al. Mutant Enpplasj mice as a model for generalized arterial calcification of infancy. Dis. Model Mech. 6, 1227-1235 (2013).

25. Li, Q., Chou, D. W., Price, T. P., Sundberg, J. P. \& Uitto, J. Genetic modulation of nephrocalcinosis in mouse models of ectopic mineralization: the Abcc6(tm1Jfk) and Enpp1(asj) mutant mice. Lab. Invest. 94, 623-632 (2014). 
26. Albright, R. A. et al. The molecular basis of purinergic signal metabolism by ecto-nucleotide pyrophosphatase/phosphodiesterases 4 and 1 and implications in stroke. J. Biol. Chem. 289, 3294-3306 (2013).

27. Folta-Stogniew, E. Oligomeric states of proteins determined by size-exclusion chromatography coupled with light scattering, absorbance, and refractive index detectors. Methods Mol. Biol. 328, 97-112 (2006).

28. Arakawa, T., Langley, K. E., Kameyama, K. \& Takagi, T. Molecular weights of glycosylated and nonglycosylated forms of recombinant human stem cell factor determined by low-angle laser light scattering. Anal. Biochem. 203, 53-57 (1992).

29. Hayashi, Y., Matsui, H. \& Takagi, T. Membrane protein molecular weight determined by low-angle laser light-scattering photometry coupled with high-performance gel chromatography. Methods Enzymol. 172, 514-528 (1989).

30. Merino, J. et al. Autoimmune syndrome after induction of neonatal tolerance to alloantigens: effects of in vivo treatment with anti-T cell subset monoclonal antibodies. J. Immunol. 139, 1426-1431 (1987).

31. Lomashvili, K. A., Narisawa, S., Millan, J. L. \& O’Neill, W. C. Vascular calcification is dependent on plasma levels of pyrophosphate. Kidney Int. 85, 1351-1356 (2014).

32. O'Neill, W. C., Sigrist, M. K. \& McIntyre, C. W. Plasma pyrophosphate and vascular calcification in chronic kidney disease. Nephrol. Dial. Transplant 25 187-191 (2010).

33. O’Neill, W. C., Lomashvili, K. A., Malluche, H. H., Faugere, M. C. \& Riser, B. L. Treatment with pyrophosphate inhibits uremic vascular calcification. Kidney Int. 79, 512-517 (2011).

34. Lomashvili, K. A., Monier-Faugere, M. C., Wang, X., Malluche, H. H. \& O'Neill, W. C. Effect of bisphosphonates on vascular calcification and bone metabolism in experimental renal failure. Kidney Int. 75, 617-625 (2009).

35. Xiao, S., White, J. F., Betenbaugh, M. J., Grisshammer, R. \& Shiloach, J. Transient and stable expression of the neurotensin receptor NTS1: a comparison of the baculovirus-insect cell and the T-REx-293 expression systems. PloS One 8, e63679 (2013).

36. Albright, R. A. et al. NPP4 is a procoagulant enzyme on the surface of vascular endothelium. Blood 120, 4432-4440 (2012).

37. Cheung, C. P. \& Suhadolnik, R. J. Analysis of inorganic pyrophosphate at the picomole level. Anal. Biochem. 83, 61-63 (1977).

38. Dobrucki, L. W. et al. Serial noninvasive targeted imaging of peripheral angiogenesis: validation and application of a semiautomated quantitative approach. J. Nucl. Med.e 50, 1356-1363 (2009).

39. Cao, W. \& De La Cruz, E. M. Quantitative full time course analysis of nonlinear enzyme cycling kinetics. Sci. Rep. 3, 2658 (2013).

\section{Acknowledgements}

These studies were financially supported by research grants from Alexion Pharmaceuticals Inc., The Connecticut Bioscience Innovation Fund, and Yale University Department of Pathology. DTB acknowledges helpful conversations with Michael Hodsdon (Eli Lily), Elias Lolis (Yale), and John Louis (NIH/NIDDK/Laboratory of Chemical Physics), and Dr Jon Morrow (Yale) for his enthusiastic support and encouragement throughout the course of this study. This material is based on work supported in part by the State of Connecticut under the Connecticut Bioscience Innovations Fund. Its contents are solely the responsibility of the authors and do not necessarily represent the official views of the State of Connecticut or Connecticut Innovations, Incorporated.

\section{Author contributions}

R.A.A., P.S., W.C., G.Y., Z.C., K.B., Z-X.Y., S.T., E.J.F.-S., A.J.S., J.S., G.Z., J.A.M., E.M.D.L.C. and D.T.B. designed the research. R.A.A, P.S., W.C., D.K., I.M., A.A.B., M.S.C., M.T., G.Y., S.T., X.W., E.J.F.-S., A.N., A.J.S., J.S., G.Z., E.M.D.L.C. and D.T.B performed the research. R.A.A., P.S., W.C., G.Y., Z.C., K.B., Z.-X.Y., S.T., X.W., E.J.F.-S., A.J.S., J.S., G.Z., J.A.M., E.M.D.L.C. and D.T.B. Analysed the data. R.A.A., P.S., W.C., Z.C., S.T., E.J.F.-S., A.J.S, J.S., G.Z., E.M.D.L.C. and D.T.B. wrote the papers.

\section{Additional information}

Supplementary Information accompanies this paper at http://www.nature.com/ naturecommunications

Competing financial interests: R.A.A. and D.T.B. are co-inventors of a pending patent application owned by Yale University related to these studies. Z.C., K.B. and Z.-X.Y. are employees of Alexion Pharmaceuticals, Inc. The remaining authors declare no competing financial interest.

Reprints and permission information is available online at http://npg.nature.com/ reprintsandpermissions/

How to cite this article: Albright, R. A. et al. ENPP1-Fc prevents mortality and vascular calcifications in rodent model of generalized arterial calcification of infancy. Nat. Commun. 6:10006 doi: 10.1038/ncomms10006 (2015).

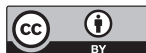

This work is licensed under a Creative Commons Attribution 4.0 International License. The images or other third party material in this article are included in the article's Creative Commons license, unless indicated otherwise in the credit line; if the material is not included under the Creative Commons license, users will need to obtain permission from the license holder to reproduce the material. To view a copy of this license, visit http://creativecommons.org/licenses/by/4.0/ 